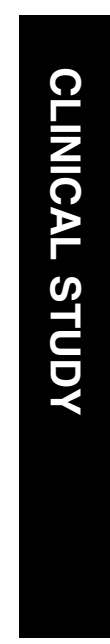

'Broomfield Hospital, Broomfield, Chelmsford, Essex, UK

${ }^{2}$ Moorfields Hospital, London, UK

${ }^{3}$ University College London, London, UK

${ }^{4}$ Central Middlesex Hospital London, UK

Correspondence: PSC Gordon-Bennett, Broomfield Hospital, Court Road, Broomfield, Chelmsford, Essex CM1 7ET, UK. Tel: 44 1245444053; Fax: 441245514898. E-mail: patelgordon@ yahoo.co.uk

Received: 17 September 2007

Accepted in revised form: 17 December 2007

Published online: 25 January 2008

\title{
A survey of investigations used for the management of glaucoma in hospital service in the United Kingdom
}

\begin{abstract}
Aims This study surveys the current use of investigations for the management of glaucoma in hospital practice by UK ophthalmologists.
\end{abstract}

Methods A total of 1007 questionnaires were posted to all active NHS consultant ophthalmologists. They were asked to indicate the type of hospital (whether university (UTH) or general (DGH) hospital), glaucoma specialist status, and availability and use of automated perimetry, disc photography, HRT, GDx, OCT, and pachymetry.

Results A total of 493 completed questionnaires were received and 469 were analysed: 284 (60.6\%) DGH, 185 (39.4\%) UTH, $144(30.7 \%)$ glaucoma specialists. There was good availability of automated perimetry $(467,99.6 \%)$, disc photography $(420,89.6 \%)$, pachymetry $(374,79.7 \%)$, OCT $(212,45.2 \%)$, HRT $(206,43.9 \%)$, and GDx (59, 12.6\%). A total of $308(65.7 \%)$ consultants had at least one digital imaging instrument available. The majority of consultants used SAP (347, $74.0 \%)$ and SITA-fast $(282,60.1 \%)$ for glaucoma suspects, and for monitoring glaucoma $(283,60.3 \%$ and $197,42.0 \%$, respectively). Some used Esterman (155, 33.0\%) and Goldmann fields $(90,19.2 \%)$ in addition to SAP and SITA-fast for glaucoma suspects. Few consultants used short-wavelength automated perimetry and frequency-doubled perimetry. Of the three imaging tests, HRT was the most commonly used investigation for disc asymmetry, early glaucoma, glaucomatous progression, ocular hypertension, normal tension glaucoma, and unreliable visual fields $(P<\mathbf{0 . 0 0 0 1})$. Where pachymeters were available, $333(89.0 \%)$ consultants
PSC Gordon-Bennett ${ }^{1}$, AS loannidis ${ }^{1,2,3}$, K Papageorgiou ${ }^{1,4}$ and PS Andreou ${ }^{1}$ and $117(98.3 \%)$ glaucoma specialists used pachymetry in glaucoma management.

Conclusions There was some variation in the use of investigations for the diagnosis and management of glaucoma, reflecting the range of techniques available. SAP, SITA-fast, and pachymetry were the most commonly utilised investigations followed by HRT. Glaucoma specialist status, type of hospital, and presence of research influenced the availability and use of all investigations, except visual fields. Eye (2008) 22, 1410-1418; doi:10.1038/sj.eye.6703089; published online 25 January 2008

Keywords: glaucoma; digital imaging; central corneal thickness; visual field; automated perimetry; pachymetry

Introduction

Current guidelines from the Royal College of Ophthalmologists, European Glaucoma Society, and the American Academy of Ophthalmology on glaucoma diagnosis and management regard stereoscopic optic disc examination and photography as the preferred methods for optic disc assessment and documentation. ${ }^{1-3}$ These guidelines recommend that at baseline examination, the use of digital computerised scanning of the disc/nerve fibre layer is optional, but visual field analysis is mandatory. The significance of psychophysical tests, such as frequency-doubled perimetry (FDT) and shortwavelength automated perimetry (SWAP), in detecting early glaucomatous field loss before standard automated perimetry (SAP) have been acknowledged by the guidelines, but their use have not been mandated. It is also recognised by these guidelines that confirmed worsening of 
optic nerve head or retinal nerve fibre layer parameters on digital scanning is a strong sign of progression, and the use of digital scanning for this purpose is recommended. The European Glaucoma Society Guidelines ${ }^{1}$ recommend central corneal thickness (CCT) measurement in certain types of glaucoma patients but not for established glaucoma.

The purpose of this study was to ascertain which of these investigations are current practice in the management of glaucoma, and whether the type of hospital, glaucoma specialist status, and presence of glaucoma research influence this practice by consultant ophthalmologists in hospital service in the United Kingdom.

To the best of our knowledge, this is the first study conducted in the United Kingdom to ascertain the investigations used for glaucoma in hospital service.

\section{Materials and methods}

In June 2006, a postal questionnaire containing 10 questions regarding the use of investigations for glaucoma, a cover letter, and a self-addressed, stamped reply envelope were sent to 1007 active consultant ophthalmologists in the UK National Health Service (NHS) and 40 consultants in private practice only. A complete and up-to-date list of all consultant ophthalmologists in the United Kingdom was obtained from the Directory of Ophthalmology Care $2006^{4}$ and the Royal College of Ophthalmologists. The study was designed to maintain anonymity for all respondents.

The first three questions asked to indicate the type of hospital, whether district general hospital (DGH) or university teaching hospital (UTH), to indicate yes or no for subspecialty interest in glaucoma, and whether glaucoma research is conducted in the department. The remaining questions were multiple choice and consultants were asked to tick as many options that were applicable. These questions obtained information on investigations available in their department for the assessment of glaucoma patients, visual field/s used to assess a patient suspected with glaucoma, visual fields to detect progression of glaucoma, and the frequency of performance of visual fields on glaucoma patients. Questions were also asked to ascertain on which patients the imaging tests, Heidelberg retinal tomography (HRT), optical coherence tomography (OCT) scanning laser polarimetry (GDx), and CCT were performed. The consultants were further asked how often they performed HRT on their glaucoma patients, and to enter any comments. Consultants were given 3 months to respond. Data obtained from the paper questionnaires were entered into a Microsoft Excel spreadsheet and statistical analysis was performed using Graphpad Software 2005. This study did not require approval from the Ethics Committee.

\section{Results}

\section{Type of hospital}

A total of 493 questionnaires were received from NHS consultant ophthalmologists, giving a response rate of $49 \%$. Only one questionnaire was received from a consultant in private practice. In total, $55 \%$ of UTH ophthalmologists and $46 \%$ of DGH ophthalmologists responded (Figure 1). A total of 16 consultants declared that they do not manage glaucoma patients and nine forms were incomplete and were excluded from further analysis. Of the 469 remaining consultants, 284 (60.6\%) were from DGH and 185 (39.4\%) were from UTH.

\section{Glaucoma subspecialty}

In total, 144 consultant ophthalmologists indicated on their questionnaire that they were glaucoma specialists. This number is similar to the number of glaucoma

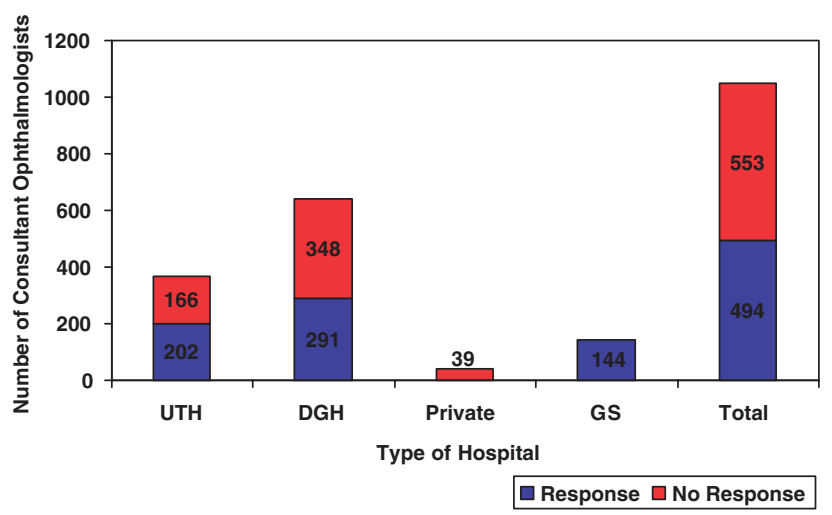

Figure 1 Responses received. 
specialists in the Royal College of Ophthalmologists' database. Sixty-four (44.4\%) consultant ophthalmologists worked in UTH, and 80 (55.6\%) in DGH. In total, 92 $(63.9 \%)$ glaucoma specialists conducted glaucoma research in their departments. A total of 161 (49.5\%) non-specialists conducted glaucoma research in their departments.

\section{Research}

In all, $253(53.9 \%)$ consultants conducted glaucoma research in their departments. Glaucoma research was more likely to be carried out in departments with glaucoma specialists $(P=0.0037)$. The majority of consultants with glaucoma research in their department was from UTH $(134,53.0 \%)$. There was no statistically significant difference between glaucoma research among UTH glaucoma specialists and DGH glaucoma specialists.

\section{Availability of investigations for glaucoma}

Table 1 shows that there was good availability of automated perimetry $(467,99.6 \%)$, disc photography $(420,89.6 \%)$, and pachymetry $(374,79.7 \%)$. In all, 308 $(65.7 \%)$ consultants had at least one digital imaging instrument available (Table 2). OCT was available to 212 (45.2\%) consultants, HRT to $206(43.9 \%)$, and GDx to 59 $(12.6 \%)$ consultants. Automated visual fields were almost equally available to DGH and UTH consultants. There was better availability of all other investigations to UTH consultants $(P<0.0001)$. Of the different types of HRT, HRT 2 was most commonly available. Only GDx showed significant availability to glaucoma specialists. There was a statistically significant effect of research on the availability of all investigations except automated visual fields.

\section{Choice of visual fields}

Standard automated perimetry was the investigation of choice for glaucoma suspects $(347,74.0 \%$; Table 3$)$ and for monitoring glaucoma $(283,60.3 \%)$. Swedish Interactive Threshold Algorithm (SITA)-fast was the second choice $(282,60.1 \%$ and $197,42.0 \%$, respectively). A total of 155 $(33.0 \%)$ consultants used Esterman and 90 (19.2\%) consultants used Goldmann fields along with SAP or SITA-fast for glaucoma suspects. No consultant used Esterman or Goldmann visual fields only. Five consultants used SWAP and 13 used FDT for glaucoma suspects, wheareas three used SWAP and four used FDT to monitor glaucoma patients. There was no significant difference in the choice of visual field between UTH and DGH consultants, or glaucoma specialists and nonspecialists.

Consultants were asked to indicate whether they performed visual fields annually, as necessary, once only, never, or to write other. Most consultants $(253,53.9 \%)$ selected as necessary, followed by annually $(132,28.1 \%)$. Most glaucoma specialists $(88,61.1 \%)$ followed the same

Table 2 Number of consultants with digital imaging available

\begin{tabular}{lc}
\hline Digital imaging instrument & Number of consultants \\
\hline HRT only & 72 \\
HRT + GDx only & 2 \\
HRT + OCT only & 104 \\
HRT + OCT + GDx & 28 \\
Total HRT & 206 \\
GDx + OCT only & 7 \\
GDx only & 22 \\
OCT only & 73 \\
Total GDx & 59 \\
Total OCT & 212 \\
No digital instrument & 163 \\
At least one digital instrument & 308 \\
\hline
\end{tabular}

Table 1 Number of consultant ophthalmologists with each glaucoma investigation and association with the type of hospital, glaucoma specialist status, and research

\begin{tabular}{|c|c|c|c|c|c|c|c|c|c|c|}
\hline $\begin{array}{l}\text { Glaucoma } \\
\text { investigation }\end{array}$ & $\begin{array}{c}\text { Number of } \\
\text { consultants } \\
\mathrm{n}=469\end{array}$ & $\begin{array}{c}\text { UTH } \\
\mathrm{n}=185\end{array}$ & $\begin{array}{c}D G H \\
\mathrm{n}=284\end{array}$ & P-value & $\begin{array}{c}\text { Glaucoma } \\
\text { specialist } \\
\mathrm{n}=144\end{array}$ & $\begin{array}{c}\text { Non-specialist } \\
\mathrm{n}=325\end{array}$ & P-value & $\begin{array}{c}\text { Research } \\
\mathrm{n}=253\end{array}$ & $\begin{array}{c}\text { No research } \\
\mathrm{n}=216\end{array}$ & P-value \\
\hline Disc photography & 420 & $182(98.4 \%)$ & $238(83.8 \%)$ & $\mathrm{S}^{* *}$ & 128 & 292 & NS & $239(94.5 \%)$ & $181(83.8 \%)$ & $S^{* *}$ \\
\hline Automated visual field & 467 & 185 & 282 & NS & 144 & 323 & NS & 252 & 215 & NS \\
\hline HRT 1,2 or 3 & 206 & $113(61.1 \%)$ & $93(32.7 \%)$ & $S^{* *}$ & 69 & 137 & NS & $145(57.3 \%)$ & $61(28.2 \%)$ & $S^{* *}$ \\
\hline GDx VCC & 59 & $34(18.4 \%)$ & $25(8.8 \%)$ & $S^{* *}$ & $32(22.2 \%)$ & $27(8.3 \%)$ & $S^{* *}$ & $44(17.4 \%)$ & $15(6.9 \%)$ & $S^{* *}$ \\
\hline OCT & 212 & $131(70.8 \%)$ & $81(28.5 \%)$ & $S^{* *}$ & 73 & 139 & NS & $149(58.9 \%)$ & $63(29.2 \%)$ & $S^{* *}$ \\
\hline СCT & 373 & $165(89.2 \%)$ & $208(73.2 \%)$ & $S^{* *}$ & 119 & 254 & NS & $219(86.6 \%)$ & $154(71.3 \%)$ & $S^{* *}$ \\
\hline
\end{tabular}

$\mathrm{S}^{* *}=$ statistically significant, $P$-value $<0.001$, Fisher's exact test, Bonferroni-adjusted $P$-value $<0.005$.

$\mathrm{NS}=$ not statistically significant, $P$-value $>0.05$, Fisher's exact test.

The percentage of consultants using each glaucoma investigation compared to the number of consultants in type of hospital, glaucoma specialty or research is given in parenthesis. 
trend, wheareas a significantly greater proportion of nonspecialists investigated annually.

\section{Digital imaging tests (HRT, OCT, and GDx)}

Of the three available digital imaging tests, HRT had the highest percentage of use (174 (84.5\%) consultants), followed by GDx $(48,81.4 \%)$ and OCT $(148,69.8 \%)$ (Table 4). The use of available HRT was significantly greater by glaucoma specialists compared to nonspecialists. There was no significant difference in the use of HRT, OCT, or GDx between UTH and DGH consultants. All three techniques were used for investigating disc asymmetry, early glaucoma, glaucomatous progression, ocular hypertension (OTN), normal tension glaucoma (NTG), and unreliable visual fields (Table 5). Of the three imaging modalities, HRT was the most commonly selected investigation by glaucoma specialists and non-specialists, for most categories of glaucoma patients $(P<0.0001)$. The most common uses of HRT by both glaucoma specialists and non-specialists were to detect progressive optic disc changes $(126,61 \%)$, and for patients with unreliable visual fields $(101,49 \%)$. GDx was most commonly used to detect early glaucomatous optic nerve changes (32, $54 \%$ ) and for patients with unreliable visual fields $(29,49 \%)$. OCT was least used for all categories of patients.

Consultants were asked to indicate whether they performed HRT annually, as necessary, once only, never, or to write other. Most consultants selected as necessary, followed by annually.

\section{CCT}

A total of $374(79.7 \%)$ consultants, including 119 (82.6\%) glaucoma specialists, reported having pachymetry available. Of these, $333(89.0 \%)$ consultants and 117 (98.3\%) glaucoma specialists measure CCT in glaucoma management. Consultants were asked whether they performed CCT on all glaucoma patients, OTN, NTG, patients with unreliable visual fields, and disc asymmetry. Most consultants responded with OTN $(195,52.1 \%)$, all glaucoma patients $(189,50.5 \%)$, and NTG

Table 3 Number of consultants using types of visual fields for glaucoma suspects and association with type of hospital and glaucoma specialist status

\begin{tabular}{|c|c|c|c|c|c|c|c|}
\hline $\begin{array}{l}\text { Type of visual } \\
\text { field }\end{array}$ & $\begin{array}{c}\text { Total } \\
\text { consultants } \\
\mathrm{n}=469\end{array}$ & $\begin{array}{c}\text { UTH } \\
\mathrm{n}=185\end{array}$ & $\begin{array}{c}D G H \\
\mathrm{n}=284\end{array}$ & P-value & $\begin{array}{c}\text { Glaucoma } \\
\text { specialists } \\
\mathrm{n}=144\end{array}$ & $\begin{array}{c}\text { Nonspecialists } \\
\mathrm{n}=325\end{array}$ & P-value \\
\hline SAP & 347 & 146 & 201 & NS & 107 & 240 & NS \\
\hline SITA-fast & 282 & 110 & 172 & NS & 90 & 192 & NS \\
\hline SWAP & 5 & 3 & 2 & NS & 2 & 3 & NS \\
\hline FDT & 13 & 4 & 9 & NS & 5 & 8 & NS \\
\hline Goldmann & 90 & 41 & 49 & NS & 33 & 57 & NS \\
\hline Esterman & 155 & 63 & 92 & NS & 43 & 112 & NS \\
\hline Armaly & 1 & 1 & 0 & NS & 0 & 1 & NS \\
\hline Other & 8 & 3 & 5 & NS & 1 & 7 & NS \\
\hline
\end{tabular}

NS $=$ not statistically significant, $P$-value $>0.05$, Fisher's exact test.

Table 4 Use of available digital imaging for glaucoma by consultant ophthalmologists

\begin{tabular}{|c|c|c|c|c|c|c|c|c|c|c|}
\hline \multirow[t]{2}{*}{ Investigation } & \multicolumn{10}{|c|}{ Number of consultants } \\
\hline & Total & $\begin{array}{c}\text { UTH } \\
n=185\end{array}$ & $\begin{array}{c}D G H \\
n=284\end{array}$ & P-value & $\begin{array}{c}\text { Glaucoma } \\
\text { specialist } \\
n=144\end{array}$ & $\begin{array}{c}\text { Non-specialist } \\
n=325\end{array}$ & P-value & $\begin{array}{c}\text { Glaucoma } \\
\text { Research } \\
n=253\end{array}$ & $\begin{array}{c}\text { No Glaucoma } \\
\text { Research } \\
n=216\end{array}$ & P-value \\
\hline HRT available & 206 & 113 & 93 & NS & 69 & 137 & $S^{* *}$ & 145 & 61 & $S^{*}$ \\
\hline HRT used & 174 & 92 & 82 & & $67(97.1 \%)$ & $107(78.1 \%)$ & & $119(82.1 \%)$ & $55(90.2 \%)$ & \\
\hline OCT available & 212 & 131 & 81 & NS & 73 & 139 & $\mathrm{~S}^{*}$ & 149 & 63 & $S^{*}$ \\
\hline OCT used & 148 & 88 & 60 & & $58(79.4 \%)$ & $90(64.7 \%)$ & & $101(67.8 \%)$ & $47(74.6 \%)$ & \\
\hline GDx available & 59 & 34 & 25 & NS & 32 & 27 & NS & 44 & 15 & NS \\
\hline GDx used & 48 & 25 & 23 & & 27 & 21 & & 38 & 10 & \\
\hline
\end{tabular}

$\mathrm{S}^{* *}=$ statistically significant, $P$-value $<0.001$, Fisher's exact test, Bonferroni-adjusted $P$-value $<0.001$.

$\mathrm{S}^{*}=$ statistically significant, $P$-value $<0.05$ and $>0.001$, Fisher's exact test, Bonferroni-adjusted $P$-value $>0.05$.

$\mathrm{NS}=$ not statistically significant, $P$-value $>0.05$, Fisher's exact test.

The percentage of consultants using digital imaging compared to the number of consultants with digital imaging available is given in parenthesis. 
Table 5 Use of HRT, OCT, and GDx for types of glaucoma patients by consultants

\begin{tabular}{|c|c|c|c|c|}
\hline Glaucoma Patient & $\begin{array}{c}\text { Number of consultants } \\
\text { using HRT }(\%)\end{array}$ & $\begin{array}{c}\text { Number of consultants } \\
\text { using OCT }(\%)\end{array}$ & $\begin{array}{c}\text { Number of consultants } \\
\text { using GDx }(\%)\end{array}$ & P-value \\
\hline Disc asymmetry & $86(41.7)$ & $37(17.4)$ & $24(40.7)$ & $S^{* *}$ \\
\hline Detection of early glaucomatous optic nerve changes & $91(44.2)$ & $40(18.9)$ & $32(54.2)$ & $\mathrm{S}^{* *}$ \\
\hline Detection of progressive optic disc changes & $126(61.2)$ & $43(20.3)$ & $23(38.9)$ & $S^{* *}$ \\
\hline Ocular hypertension & $92(44.7)$ & $31(14.6)$ & $23(38.9)$ & $\mathrm{S}^{* *}$ \\
\hline Normal tension glaucoma & $96(46.6)$ & $37(17.4)$ & $22(37.3)$ & $S^{* *}$ \\
\hline Unreliable visual fields & $101(49.0)$ & $41(19.3)$ & $29(49.2)$ & $S^{* *}$ \\
\hline I do not use this test & $30(14.6)$ & $63(29.7)$ & $11(18.6)$ & $S^{*}$ \\
\hline Total number of consultants with & 206 & 212 & 59 & \\
\hline
\end{tabular}

investigation available

$\mathrm{S}^{* *}=$ statistically significant, $P$-value $<0.001, \chi^{2}$ test, $2 \mathrm{df}$. Bonferroni-adjusted $P$-value $<0.001$.

$\mathrm{S}^{*}=$ statistically significant, $P$-value $<0.05$ and $>0.001$, chi-square test, $2 \mathrm{df}$. Bonferroni-adjusted $P$-value $<0.05$.

The percentage of consultants using digital imaging compared to the number of consultants with digital imaging available is given in parenthesis.

$(155,41.4 \%)$. A significantly greater proportion of UTH consultants and glaucoma specialists measure CCT on all glaucoma patients, wheareas DGH consultants measure CCT in NTG and OTN.

\section{Discussion}

The purpose of this study was to determine the differences or similarities in the use of various diagnostic techniques between types of hospitals, and to establish whether the presence of a glaucoma specialist or glaucoma research in an ophthalmology unit are factors in the choice of investigations used. From the analysis of the data obtained from this sample, it is evident that the presence of a glaucoma specialist in the department did not seem to influence the availability of most investigations, with the exception of GDx. UTHs were better equipped with digital imaging, pachymetry, and disc photography than DGHs. Departments with glaucoma research were also better equipped. Two-thirds of glaucoma specialists had glaucoma research in their department.

\section{Choice of visual field}

SAP was preferred to SITA-fast for monitoring glaucoma and for investigating glaucoma suspects. A number of consultants and glaucoma specialists used Esterman and Goldmann visual fields along with either SAP or SITAfast, to monitor glaucoma suspects. A possible explanation is that Esterman is a binocular test and is used to assess driving capacity in the United Kingdom; however, Esterman and Goldmann visual fields provide little information about early glaucomatous field defects. By contrast, SWAP and FDT, which are known to detect very early glaucomatous field defects before $\mathrm{SAP}^{5}$ and possibly before digital imaging ${ }^{6,7}$ were used by a small number of consultants. This may be due to the longer time taken to perform SWAP compared to SAP and the low availability of FDT in the United Kingdom. One study compared SAP, SWAP, and FDT and found that FDT showed the highest sensitivity overall. ${ }^{8}$

\section{Digital imaging instruments}

Optic nerve head photography was two times more available than digital imaging and still seems to be the mainstay of optic nerve head imaging. OCT was the most available digital imaging modality but was slightly less used than HRT in glaucoma management. A likely explanation is that OCT has a wider clinical application in other subspecialties and is therefore more available, but is probably used more commonly for retinal conditions than for glaucoma. The less common use of OCT for glaucoma compared to HRT becomes more evident on direct questioning about different categories of glaucoma patients in question 8 of the questionnaire. The clinical applications of imaging are screening for glaucoma, diagnosis of glaucoma, and detection of glaucomatous progression. Of the three digital imaging devices, HRT was the most commonly used investigation by consultants in this survey to evaluate glaucoma patients, primarily for the detection of glaucomatous progression and for patients with unreliable visual fields. The reason may be that, of the three modalities, HRT is the most advanced technology. HRT was introduced in 1991 and was updated to HRT 2 in 1999, wheareas GDx was introduced in 1992 and OCT in 1995. In addition, GDx and OCT have had a number of software and hardware alterations over a short time span.

HRT 2 has been shown to have a sensitivity of $84 \%$ and a specificity of $96 \%$ and is more sensitive than clinical assessment of stereoscopic optic disc photographs in detecting early glaucoma when compared with normals defined by visual field status, ${ }^{9}$ although other studies suggest otherwise. ${ }^{10}$ Some studies have suggested that 
HRT 2 can be used as a screening tool to diagnose early perimetric glaucoma ${ }^{11}$ as well as preperimetric glaucoma. ${ }^{12}$ It has been shown that baseline HRT measurements are predictive of glaucomatous changes in ocular hypertensives without detectable functional damage. ${ }^{13}$ Several studies have reported the ability of HRT to detect progression. ${ }^{14,15}$ HRT is better in detecting glaucomatous progression than expert clinicians viewing stereophotos, ${ }^{16}$ and detects progression earlier than SAP. $^{14}$

GDx discriminates well between normal and glaucomatous eyes, ${ }^{17}$ can be used to diagnose early preperimetric glaucoma, ${ }^{18}$ and can predict glaucomatous visual field loss in glaucoma suspects. ${ }^{19}$ There are few studies exhibiting its ability to identify and monitor glaucomatous progression because of its recent introduction. GDx VCC is better at detecting nerve fibre layer loss than retinal nerve fibre layer photography, ${ }^{20}$ and may be used as a screening tool, as it has been shown to have $89 \%$ sensitivity and $96 \%$ specificity, $^{21}$ but preferably not in isolation. ${ }^{22}$

There are differences in the measurement of the peripapillary retinal nerve fibre layer thickness between Stratus OCT and GDx VCC, but the diagnostic accuracy of the best parameters of the two modalities is similar. ${ }^{23}$ OCT can discriminate between normal and glaucomatous eyes, ${ }^{24}$ but there are few longitudinal studies suggesting that it can identify glaucomatous progression. ${ }^{25}$ To our knowledge, there are no published studies on the ability of the recently introduced Stratus OCT to detect glaucoma progression.

\section{Comparison of HRT, OCT, and GDx}

The ability to distinguish healthy eyes from those with glaucomatous field loss were similar among the best parameters for each instrument. ${ }^{24,26}$ One study showed that although the diagnostic abilities of the three imaging modalities were similar, assessment of stereophotographs and measurements from OCT and HRT had higher sensitivities than measurements from GDx. ${ }^{27}$ A combination of the imaging methods significantly improves the ability to distinguish normal eyes from early - to moderate glaucoma. ${ }^{28}$ When used alone, HRT, GDx and OCT can differentiate between normal and early-moderate glaucoma, but none of the instruments are sensitive or specific enough to be used as a screening tool for early-moderate glaucoma. ${ }^{29}$ More severe visual field loss is associated with increased sensitivity of all imaging instruments. It has been shown that structure-function relationships are significantly strongest for Stratus OCT measurements and similar between HRT 2 and GDx VCC for glaucoma suspects and patients. ${ }^{30,31}$ Large optic discs are associated with decreased sensitivity for the best parameters of the Stratus OCT and GDx VCC, whereas small optic discs are associated with increased sensitivity. For HRT 2, an inverse effect is observed. ${ }^{32}$

A combination of structural and functional tests improves the ability to detect glaucoma. Adding either FDT or SWAP to each of the digital imaging modalities led to an increase in the sensitivity of glaucoma detection. $^{33}$

\section{CCT}

Recent studies have shown that CCT is essential in the evaluation of glaucoma. CCT is a confounder of Goldmann applanation tonometry (GAT), and omitting its measurement may lead to the overdiagnosis, underdiagnosis, or misclassification of glaucoma, especially after refractive surgery. It is also important to measure CCT to determine the target IOP for each patient.

CCT has also been shown by the OHTS study to be a potent predictor of glaucoma risk, ${ }^{34}$ and is inversely related to the risk of developing glaucomatous damage. The role of CCT as a predictor of glaucoma development was also confirmed by studies, which showed that ocular hypertensive patients exhibiting early glaucomatous damage on FDT, SWAP, ${ }^{5,35}$ and $\mathrm{OCT}^{36}$ had thinner corneas than those with normal tests. CCT is important in the management of preperimetric glaucomatous optic neuropathy, as it has been shown that patients who develop early SAP defects have thinner corneas. ${ }^{37}$

CCT also gives an indication of the robustness of the optic nerve and is inversely associated with glaucomatous optic neuropathy, larger disc size, and a more deformable disc. ${ }^{38}$ Corneal hysteresis has been shown to be inversely associated with visual field progression. ${ }^{39}$

\section{Implications for clinical practice}

The National Institute for Clinical Excellence is currently evaluating a data set for glaucoma. This survey represents a snapshot of current practice and we believe that the data may provide some helpful information about the current use of technology in some of the ophthalmology clinics in the United Kingdom. The data may also help to formulate a consensus about diagnostic imaging in glaucoma management in the United Kingdom.

In this sample, we believe the response rate from glaucoma specialists was high; however, as the survey was anonymous, we could not establish the overall proportion of UK glaucoma specialists who responded to the study. Another limitation of this survey 
was the large study population with an overall response rate of just under 50\%. From this sample, only 16 ophthalmologists indicated that they do not manage glaucoma patients. We suspect that a significant number of non-responders belong to this group of ophthalmologists. No attempt was made to recontact non-responders as their identity was kept anonymous. As only one response was received from the a consultant in private practice, no study or comparison could be made with that practice pattern. The questionnaire was limited to 10 questions in an effort to increase compliance, and were multiple choice with additional space to allow responses not listed. We were particularly interested in the availability and use of digital imaging, visual fields, and CCT. Tonometry, corneal hysteresis, and gonioscopy were excluded from the survey.

\section{Conclusions}

From this study, there seems to be some variation in the use of investigations for the diagnosis and management of glaucoma reflecting the range of techniques available. SAP, SITA-fast, pachymetry, and HRT were the most commonly utilised investigations. Glaucoma specialist status, type of hospital, and presence of research influenced the availability and use of some investigations.

The data from this survey suggest that consultants with subspecialist interest in glaucoma were more likely to conduct glaucoma research. Of all the glaucoma equipment, only GDx was more likely to be available where a glaucoma specialist was present. The choice of visual fields and digital imaging equipment was similar between glaucoma specialists and non-specialists. Glaucoma specialists chose SAP, which was closely followed by SITA-fast, for glaucoma suspects and glaucoma monitoring. Some added Esterman fields for glaucoma suspects, presumably to assess the driving standard. SWAP and FDT were rarely used. Glaucoma specialists showed significantly greater use of available HRT and OCT than non-specialists. Of the three digital techniques, HRT was most commonly used by both specialists and non-specialists, and the leading use by glaucoma specialists was for glaucomatous progression, followed by unreliable fields, disc asymmetry, OTN, NTG, and early glaucoma. Almost all glaucoma specialists measured CCT in glaucoma management, and do so on all glaucoma patients.

\section{Acknowledgements}

We thank Siobhan Stubbings of the Clinical Audit Department at Broomfield Hospital for collecting all the questionnaires and documenting the data on to spreadsheets. A donation of $£ 600$ was contributed to this project by the Research and Development Department at Broomfield Hospital.

\section{Competing interest}

The authors have no proprietary a financial interest in any of the products named.

\section{References}

1 Patient Examination. In: European Glaucoma Society. Terminology and Guidelines for Glaucoma, 2nd edn. Dogma: Italy, 2003, pp 1-3-1-35.

2 American Academy of Ophthalmology. Primary Open Angle Glaucoma, Preferred Practice Pattern. American Academy of Ophthalmology: San Francisco, 2005.

3 The Scientific Department, Royal College of Ophthalmologists. Guidelines for the Management of Open Angle Glaucoma and Ocular Hypertension. Royal College of Ophthalmologists: London, 2004.

4 Directory of Ophthalmology Care 2006. CMA Medical Data: Loughborough, 2006.

5 Medeiros FA, Sample PA, Weinreb RN. Frequency doubling technology perimetry abnormalities as predictors of glaucomatous visual field loss. Am J Ophthalmol 2004; 137(5): 863-871.

6 Cellini M, Bernabini B, Carbonelli M, Zamparini E, Campos EC. Optical coherence tomography, frequencydoubling technology, and colour Doppler imaging in ocular hypertension. Eye 2007; 21(8): 1071-1077.

7 Teesalu P, Airaksinen PJ, Tuulonen A. Blue-on-yellow visual field and retinal nerve fiber layer in ocular hypertension and glaucoma. Ophthalmology 1998; 105(11): 2077-2081.

8 Sample PA, Medeiros FA, Racette L, Pascual JP, Boden C, Zangwill LM et al. Identifying glaucomatous vision loss with visual-function-specific perimetry in the diagnostic innovations in glaucoma study. Invest Ophthalmol Vis Sci 2006; 47(8): 3381-3389.

9 Wollstein G, Garway-Heath DF, Fontana L, Hitchings RA. Identifying early glaucomatous changes. Comparison between expert clinical assessment of optic disc photographs and confocal scanning ophthalmoscopy. Ophthalmology 2000; 107(12): 2272-2277.

10 Kesen MR, Spaeth GL, Henderer JD, Pereira ML, Smith AF, Steinmann WC. The Heidelberg retina tomograph vs clinical impression in the diagnosis of glaucoma. Am J Ophthalmol 2002; 133(5): 613-616.

11 Garway-Heath DF, Hitchings RA. Quantitative evaluation of the optic nerve head in early glaucoma. $\mathrm{Br}$ J Ophthalmol 1998; 82(4): 352-361.

12 Bowd C, Zangwill LM, Medeiros FA, Hao J, Chan K, Lee TW et al. Confocal scanning laser ophthalmoscopy classifiers and stereophotograph evaluation for prediction of visual field abnormalities in glaucoma-suspect eyes. Invest Ophthalmol Vis Sci 2004; 45(7): 2255-2262.

13 Zangwill LM, Weinreb RN, Beiser JA, Berry CC, Cioffi GA, Coleman AL et al. Baseline topographic optic disc measurements are associated with the development of primary open-angle glaucoma: the Confocal Scanning Laser 
Ophthalmoscopy Ancillary Study to the Ocular Hypertension Treatment Study. Arch Ophthalmol 2005; 123(9): 1188-1197.

14 Chauhan BC, McCormick TA, Nicolela MT, LeBlanc RP. Optic disc and visual field changes in a prospective longitudinal study of patients with glaucoma: comparison of scanning laser tomography with conventional perimetry and optic disc photography. Arch Ophthalmol 2001; 119(10): 1492-1499.

15 Patterson AJ, Garway-Heath DF, Strouthidis NG, Crabb DP. A new statistical approach for quantifying change in series of retinal and optic nerve head topography images. Invest Ophthalmol Vis Sci 2005; 46(5): 1659-1667.

16 Ervin JC, Lemij HG, Mills RP, Quigley HA, Thompson HW, Burgoyne CF. Clinician change detection viewing longitudinal stereophotographs compared to confocal scanning laser tomography in the LSU Experimental Glaucoma (LEG) Study. Ophthalmology 2002; 109(3): 467-481.

17 Tannenbaum DP, Hoffman D, Lemij HG, Garway-Heath DF, Greenfield DS, Caprioli J. Variable corneal compensation improves discrimination between normal and glaucomatous eyes with the scanning laser polarimeter. Ophthalmology 2004; 111(2): 259-264.

18 Medeiros FA, Zangwill LM, Bowd C, Sample PA, Weinreb $\mathrm{RN}$. Use of progressive glaucomatous optic disk change as the reference standard for evaluation of diagnostic tests in glaucoma. Am J Ophthalmol 2005; 139(6): 1010-1018.

19 Mohammadi K, Bowd C, Weinreb RN, Medeiros FA, Sample PA, Zangwill LM. Retinal nerve fiber layer thickness measurements with scanning laser polarimetry predict glaucomatous visual field loss. Am J Ophthalmol 2004; 138(4): 592-601.

20 Medeiros FA, Zangwill LM, Bowd C, Mohammadi K, Weinreb RN. Comparison of scanning laser polarimetry using variable corneal compensation and retinal nerve fiber layer photography for detection of glaucoma. Arch Ophthalmol 2004; 122(5): 698-704.

21 Reus NJ, Lemij HG. Diagnostic accuracy of the GDx VCC for glaucoma. Ophthalmology 2004; 111(10): 1860-1865.

22 Shaikh A, Salmon JF. The role of scanning laser polarimetry using the GDx variable corneal compensator in the management of glaucoma suspects. Br J Ophthalmol 2006; 90(12): 1454-1457.

23 Leung CK, Chan WM, Chong KK, Yung WH, Tang KT, Woo $\mathrm{J}$ et al. Comparative study of retinal nerve fiber layer measurement by StratusOCT and GDx VCC, I: correlation analysis in glaucoma. Invest Ophthalmol Vis Sci 2005; 46(9): 3214-3220.

24 Medeiros FA, Zangwill LM, Bowd C, Weinreb RN. Comparison of the GDx VCC scanning laser polarimeter, HRT II confocal scanning laser ophthalmoscope, and stratus OCT optical coherence tomograph for the detection of glaucoma. Arch Ophthalmol 2004; 122(6): 827-837.

25 Wollstein G, Schuman JS, Price LL, Aydin A, Stark PC, Hertzmark E et al. Optical coherence tomography longitudinal evaluation of retinal nerve fiber layer thickness in glaucoma. Arch Ophthalmol 2005; 123(4): 464-470 Erratum in: Arch Ophthalmol 2005; 123(9): 1206.

26 Pueyo V, Polo V, Larrosa JM, Ferreras A, Martinez-de-laCasa JM, Honrubia FM. Diagnostic usefulness of optical coherence tomography (OCT), scanning laser tomography (HRT-II) and laser polarimetry (GDx) in openangle glaucoma. Arch Soc Esp Oftalmol 2006; 81(12): 693-700.
27 Zangwill LM, Bowd C, Berry CC, Williams J, Blumenthal EZ, Sánchez-Galeana CA et al. Discriminating between normal and glaucomatous eyes using the heidelberg retina tomograph, GDx nerve fiber analyzer, and optical coherence tomograph. Arch Ophthalmol 2001; 119(7): 985-993.

28 Greaney MJ, Hoffman DC, Garway-Heath DF, Nakla M, Coleman AL, Caprioli J. Comparison of optic nerve imaging methods to distinguish normal eyes from those with glaucoma. Invest Ophthalmol Vis Sci 2002; 43(1): 140-145.

29 Sanchez-Galeana C, Bowd C, Blumenthal EZ, Gokhale PA, Zangwill LM, Weinreb RN. Using optical imaging summary data to detect glaucoma. Ophthalmology 2001; 108(10): 1812-1818.

30 Bowd C, Zangwill LM, Medeiros FA, Tavares IM, Hoffmann EM, Bourne RR et al. Structure-function relationships using confocal scanning laser ophthalmoscopy, optical coherence tomography, and scanning laser polarimetry. Invest Ophthalmol Vis Sci 2006; 47(7): 2889-2895.

31 Leung CK, Chong KK, Chan WM, Yiu CK, Tso MY, Woo J et al. Comparative study of retinal nerve fiber layer measurement by StratusOCT and GDx VCC, II: structure/ function regression analysis in glaucoma. Invest Ophthalmol Vis Sci 2005; 46(10): 3702-3711.

32 Medeiros FA, Zangwill LM, Bowd C, Sample PA, Weinreb $\mathrm{RN}$. Influence of disease severity and optic disc size on the diagnostic performance of imaging instruments in glaucoma. Invest Ophthalmol Vis Sci 2006; 47(3): 1008-1015.

33 Shah NN, Bowd C, Medeiros FA, Weinreb RN, Sample PA, Hoffmann EM et al. Combining structural and functional testing for detection of glaucoma. Ophthalmology 2006; 113(9): 1593-1602.

34 Gordon MO, Beiser JA, Brandt JD, Heuer DK, Higginbotham EJ, Johnson CA et al. The Ocular Hypertension Treatment Study: baseline factors that predict the onset of primary open-angle glaucoma. Arch Ophthalmol 2002; 120(6): 714-720; discussion 829-830. Comment in: Arch Ophthalmol 2004; 122(7): 1088-1089; author reply 1089.

35 Medeiros FA, Sample PA, Weinreb RN. Corneal thickness measurements and visual function abnormalities in ocular hypertensive patients. Am J Ophthalmol 2003; 135: 131-137.

36 Kaushik S, Gyatsho JA, Jain RA, Pandav SS, Gupta AM. Correlation between retinal nerve fiber layer thickness and central corneal thickness in patients with ocular hypertension: an Optical Coherence Tomography Study. Am J Ophthalmol 2006; 141(5): 884-890; e-pub ahead of print 20 March 2006.

37 Medeiros FA, Sample PA, Zangwill LM, Bowd C, Aihara M, Weinreb RN. Corneal thickness as a risk factor for visual field loss in patients with preperimetric glaucomatous optic neuropathy. Am J Ophthalmol 2003; 136(5): 805-813.

38 Pakravan M, Parsa A, Sanagou M, Parsa CF. Central corneal thickness and correlation to optic disc size: a potential link for susceptibility to glaucoma. Br J Ophthalmol 2007; 91(1): 26-28; e-pub ahead of print 14 September 2006.

39 Congdon NG, Broman AT, Bandeen-Roche K, Grover D, Quigley HA. Central corneal thickness and corneal hysteresis associated with glaucoma damage. Am J Ophthalmol 2006; 141(5): 868-875; e-pub ahead of print 9 March 2006. 


\section{Appendix}

This is the questionnaire that was posted to all consultant ophthalmologists

Glaucoma investigations in hospital service-a UK survey

Please tick all options that apply.

1. Type of hospital

District general

hospital

Independent hospital

2. Do you have a subspecialty interest in glaucoma?

3. Is glaucoma research conducted in your department?

4. What investigations are available in your department for the assessment of glaucoma?

Disc photography

automated visual fields

HRT (Heidelberg retinal tomography)

If yes:

HRT 1

Yes

Yes

GDx VCC (scanning laser polarimetry)

OCT (optical coherence tomography or Stratus)

Central corneal thickness

Phasing

None of the above

5. What visual field/s do you use to assess a patient in whom you suspect glaucoma?

(a) SAP (standard automated perimetry)

Please select which type:

24-2

(b) SITA-fast

(c) SWAP (short-wavelength automated perimetry or blue-on-yellow)

(d) FDT (frequency-doubling technology)

(e) Goldmann manual perimetry

(f) Binocular field

Please select which type: Esterman

(g) Other

6. Which visual field/s do you use to monitor glaucoma or detect progression?

(Please select from options a-g in question number 5).

7. How often do you perform visual fields on glaucoma patients?

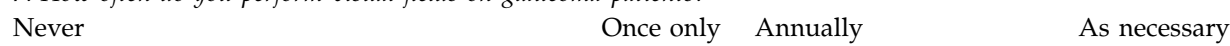

Other

8. In which patient/s do you use HRT, OCT, and GDx?

HRT

OCT

Please tick all that apply.

I do not use this test

In patients with disc asymmetry

To detect early glaucomatous optic nerve changes

To detect progressive optic disc changes

Ocular hypertension

Normal tension glaucoma

Unreliable visual fields

Other

9. In which patients do you perform central corneal thickness?

I do not use this test

In patients with disc asymmetry

On all glaucoma patients

Ocular hypertension

Normal tension glaucoma

Unreliable visual fields

Other

10. How often do you perform HRT on a glaucoma suspect?

Never

Once only Annually

Other

11. Comments:
No

No

30-2

University teaching hospital

HRT 3

Armaly 